\title{
PSYCHOLOGICAL ADJUSTMENT OF EXPATRIATE CHILDREN IN CULTURAL TRANSITIONS
}

\section{Anu Warinowski and Eero Laakkonen}

\begin{abstract}
The aim of the current study was to define the factorial structure of the psychological adjustment (PA) of Finnish expatriate children (EC) and to construct a model consisting of three child-level variables (age, school success, and attitude toward moving). Survey data concerning Finnish EC $(N=324)$ who had lived temporarily abroad were gathered from the EC's parents. The mean age of the children was 4.8 years in the expatriation context and 8.2 years in the repatriation context. PA was examined using the Zung Self-Rating Depression Scale (ZSDS). Survey data were subject to a confirmatory factor analysis (CFA) and structural equation modeling (SEM). A hypothesized two-factor structure (physiological and affective factors) of PA was fitted for the sample using the CFA. A SEM of PA was presented, where the child-level explanatory variables were the age of the child, school success, and attitude toward moving. The main findings were the following: First, there is a two-factor structure of Finnish EC's PA with both physiological and affective factors. Second, a model of PA with three child-level variables (age, school success, and attitude toward moving) was constructed. The results contribute to the understanding of PA in general and EC's PA in particular. This study increases our understanding of EC's PA in unique and novel contexts of dual cultural transitions. This comprehension is important in an increasingly globalized world, especially in clinical and other support contexts, where professionals work for children's mental well-being.
\end{abstract}

Keywords: psychological adjustment, expatriate children, cultural transition, expatriation, repatriation

Anu Warinowski PhD (the corresponding author) is Head of Faculty Development in the Faculty of Education at the University of Turku. Address: Assistentinkatu 5, 20014 University of Turku, Finland. Email: anu.warinowski@utu.fi

Eero Laakkonen is Special Researcher in the Department of Teacher Education at the University of Turku. Address: Assistentinkatu 5, 20014 University of Turku, Finland. Email: eerlaa@utu.fi 
International Journal of Child, Youth and Family Studies (2020) 11(1): 1-22

We are living in a global era of increasing international mobility and intercultural contact (e.g., Ward \& Kagitcibasi, 2010). Contemporary migration has become diverse, complex, and temporary in nature. Because of globalization, the number of internationally mobile employees has increased worldwide (e.g., Warinowski, 2011a). Thus, contemporary migration includes millions of short-term immigrants connected by their global working lives, including expatriates and their family members (e.g., Ward \& Kagitcibasi, 2010). In the present study, expatriates are defined as contemporary labor-based temporary migrants, a subgroup of migrants in general (Warinowski, 2011a). Although they have many similarities with other migrant groups, they do have two distinct features: the temporal nature of the move, and work as the reason for moving. Expatriates typically move with their families, which include a spouse and at least one child (e.g., Suutari \& Brewster, 2003).

Expatriate children (EC) refers to children who move abroad temporarily with their families because of a parent's work. In previous studies, several terms have been used for these children, such as American-based "third culture kids" (TCK; for the history of this term, see Kano Podolsky, 2004; Brown \& Lauder, 2009) and "global nomads" (Fail, 2007). Given that the cultural situation that is part of living abroad differs for American English-speaking children and Finnish Finnish-speaking children, these concepts do not suit the Finnish EC's context because of differences in language situation (English as a lingua franca vs. Finnish as a minor language) and expatriate community size (large American expatriate communities vs. few other Finnish expatriates; Warinowski, 2011b). However they are conceptualized, all these children serve as agents of globalization (Kano Podolsky, 2004; see also Brown \& Lauder, 2009). Nevertheless, few studies that are linked with acculturation have focused on EC. In our study, acculturation is defined according to Chirkov (2009a) as a multifaceted, continuous process that begins after one enters a cultural context that differs from the cultural context where one was initially socialized. We understand "culture" as dynamic, situated, and context bound. It includes multifaceted in-group differences in, for example, ethnicity, language, and family dynamics (e.g., Nieto, 2008). With this in mind, transitions between two cultural contexts (Finland and abroad) are conceptualized in our study as cultural transitions, and EC in cultural transitions are viewed as undergoing diverse, simultaneous changes of different forms (Grimshaw \& Sears, 2008; Nette \& Hayden, 2007).

As a number of seminal studies have noted, cultural transitions connect conceptually with the notion of adaptation (Ward \& Kennedy, 1993a, 1993b; Ward et al., 1998). Ward and colleagues (1998) made a broad distinction between two types of adaptation — psychological and sociocultural — that are required during cultural transitions ( see also Chiu et al., 2013; Searle \& Ward, 1990; Ward \& Kennedy, 1993a, 1994; Ward \& Searle, 1991). Accordingly, acculturation research has traditionally examined two adaptational outcomes in cultural contexts: psychological adjustment (PA) and sociocultural adaptation (e.g., Searle \& Ward, 1990; Schwartz et al., 2010). Although these two dimensions of adaptation are linked, it has also been suggested that one should approach them as separate theoretical concepts (Ward \& Kennedy, 1993a). In making the needed 
International Journal of Child, Youth and Family Studies (2020) 11(1): 1-22

distinction between the two dimensions, PA is conceptualized as an affective process in cultural transitions and is linked with a person's psychological well-being; it is defined here as a person's psychological well-being and emotional contentment (Ward \& Kennedy, 1993a; Ward et al., 1998). It encompasses depression, life satisfaction, self-esteem, loneliness, and negative affect (Nguyen \& Benet Martínez, 2013). In short, PA focuses on "feeling well" in a transitional context (Chiu et al., 2013). Typically, difficulties in PA constitute the main problems with immigrant children's adjustment (e.g., Berry et al., 2006). This is why our current study also focuses on PA.

Although there has been extensive research on cultural transitions, it has tended to focus on first, a single transition (e.g., König, 2009), and, second, the effects of transitions on adults (Dobson, 2009) rather than children. The present study tries to fill these two gaps with its focus on children and on the linked transitions of moving from one's culture of origin (expatriation) and afterwards, having lived in the other culture, returning to the original location (repatriation) with perhaps a very different way of experiencing the world.

Expatriation research has used the concepts of expatriation and repatriation widely. As a phase of cultural transition, expatriation is defined here as moving away from one's passport country; repatriation, then, means moving back to the passport country. Thus, for EC, important changes occur not once but twice. This dual nature of EC's cultural transitions gives them extra challenges compared with a person having only one transition. In expatriation research, the focus has tended to be on the expatriation stage only, thus largely neglecting repatriation (Szkudlarek, 2010). Only a few studies have emphasized both transitions. These studies considered cultural identities in the processes of expatriation and repatriation of American teachers who sojourned in Japan (Sussman, 2002) and children (Fail, Thompson, \& Walker, 2004; Kanno, 2000; see also König, 2009).

The extant research allows us to compare adults versus children in cultural transitions. Changing residences is widely known to be a stressful experience for adults (e.g., Oishi et al., 2012). For children, who normally lack control over decisions about moving, it is bound to be more demanding, possibly even traumatic (Oishi et al., 2012). Transitions can have more severe and long-lasting effects on children than on adults (Grimsaw \& Sears, 2008; Nette \& Hayden, 2007). Nevertheless, acculturation studies have mainly focused on adults (Dobson, 2009). Futhermore, until Shah and Lund (2007) and Haslberger and Brewster (2008) began to look at expatriate families, expatriate research largely focused on single individuals. Despite this development, in the field of expatriate research, children are generally viewed as "luggage" something that adults must take with them when they move abroad and when they return to their country of origin (Selmer \& Lam, 2004).

From the viewpoints of both childhood studies and current cross-cultural psychology, individuals are seen as active agents in cultural transitions, and acculturation and adjustment are seen as active processes. Individual acculturation is a process that an agentic individual executes (Chirkov, 2009a). In cultural transitions and within the context of the current study, EC are seen 
International Journal of Child, Youth and Family Studies (2020) 11(1): 1-22

from a dynamic and agentic view, combining a contextual, cultural view with a child-level approach (Kagitcibasi, 2005). Many childhood studies have used qualitative data, but there has been a recent demand for more methodological variation (e.g., Clark et al., 2014). Taking a childlevel approach in research and using quantitative data are techniques that have not often been applied in this research area. Thus, in the present study, we used quantitative data to analyze the child-level variables for PA. Also, the PA experiences of EC have not been sufficiently researched in the context of EC in general and in the Finnish EC context particularly. Previously, we have studied the correlations of PA with several family- and individual-level variables (Warinowski, 2012). Among these correlations, individual-level variables of age, school success, and attitude toward moving were found to be worthy of more thorough research.

\section{Present Investigation}

The aim of our study was to define the factorial structure of Finnish EC's PA and construct a model consisting of three child-level variables (age, school success, and attitude toward moving) in cultural transitions of expatriation and repatriation. From these objectives, related research questions arise.

The first research question is: (Q1) What is the factorial structure of the PA of Finnish EC? For PA, the Zung Self-Rating Depression Scale (ZSDS; Zung, 1972; see "Measures" below) was used. Cross-cultural studies have been adopting this scale for decades (MacBeth \& Gumley, 2012). It is a traditional and still widely used measure for PA. Indeed, it remains one of the most prevalent scales for measuring PA (e.g., Demes \& Geeraert, 2013). Colleen Ward, a pioneer of the PA research field, has used this scale in her studies on PA (e.g., Ward et al., 1998; Ward \& RanaDeuba, 1999). Ward has continuously demonstrated the reliability of this scale in her sojourner studies (Ward \& Kennedy, 1992; Ward et al., 2004; Ward \& Searle, 1991). Although the ZSDS has been in use for decades, the factor structure of the ZSDS remains unestablished (see "Measures" for the factor structure used in this study). There have been different findings regarding the factor structure of the ZSDS. Researchers have found two-factor (Chida et al., 2004; Zung, 1972), three-factor (Kitamura et al., 2004; Ward et al., 2004; Ward \& Rana-Deuba, 1999), and four-factor structures (Passik et al., 2000; Romera et al., 2008). They have also found cultural variations in the factor structure (e.g., Zung, 1972). However, two factors - affective and cognitive - have been fairly consistent in several studies (Kitamura et al., 2004). A hypothesis in the present study is that (H1) a two-factor structure of the ZSDS (Chida et al., 2004; Zung, 1972) could fit the sample. This hypothesis is based on the results of previous studies, contents of the items, and the preliminary examination of the items (for the preliminary analyses, see Warinowski, 2012).

The second research question is the following: (Q2) What kind of a model can be constructed using three child-level variables (age, school success, and attitude toward moving) that link with EC's PA in the cultural transitions of expatriation and repatriation? Although researchers 
International Journal of Child, Youth and Family Studies (2020) 11(1): 1-22

have been studying PA for decades, they have neglected the psychological mechanisms that explain the relationship between acculturation and psychological well-being (Yoon et al., 2008). We hypothesize that (H2) a model of PA would consist of the child-level variables of age (e.g., Warinowski, 2012), school success (e.g., Fröjd et al., 2008; McCarty et al., 2008), and attitude toward moving (e.g., Warinowski, 2012).

Our research examines three child-level variables: age, school success, and attitude toward transitions. These three variables are potentially important predictors of PA; Warinowski (2012) found that they correlate with PA. However, the fact that few previous studies linked these variables with PA makes it difficult to predict the exact contribution of each one to PA.

Age: Age is linked with other time measures, such as the duration of living abroad. Although PA does not follow a special temporal stage model (Searle \& Ward, 1990; Ward \& Kennedy, 1992, 1993a, 1994), some studies have shown that immigrants' psychological adjustment increases over time. However, this pattern is not clear among adolescents.

School success: Concerning children's success in school, research has uncovered the mutual interplay between failure and psychological functioning (McCarty et al., 2008). Past studies have also revealed links between psychological adjustment and achievement (Costigan et al., 2010).

Attitude toward transitions: Children's attitudes toward moving abroad and back to their country of origin are part of the affective processes of PA (Warinowski, 2012). EC's attitude toward moving can have some relevance to their PA. In a previous study, one-third of the EC reacted negatively, but the researchers found no correlation between attitude and well-being (Nathanson \& Marcenko, 1995).

In addition to its close links with acculturation psychology and cross-cultural psychology, our study included research from other disciplines such as childhood studies and expatriate research to better understand the cultural transitions that EC undergo. Indeed, there is a general consensus that multidisciplinary research is important for enhancing acculturation research (Bhatia \& Ram, 2009; Chirkov, 2009a; Weinreich, 2009).

\section{Subjects and Procedure}

The target group of our current study was Finnish expatriate families, especially their children. Although cultural contexts matter, previous acculturation studies have largely ignored the context of the acculturation process (Bhatia \& Ram, 2009; Chirkov, 2009a, 2009b; Weinreich, 2009). Researchers have criticized a "one-size-fits-all" perspective on acculturation and suggested using a more nuanced approach (Chirkov, 2009b). Both the TCK research and the cultural transition research (Allik, 2013; Yoon et al., 2011) have had an America-centric context, whereas the European perspective has been largely absent. In particular, a pressing need for research on 
International Journal of Child, Youth and Family Studies (2020) 11(1): 1-22

non-English-speaking mobile children's issues has been previously identified (cf. Murphy, 2003). Hence, the present study concentrates on a non-English-speaking, European group of EC.

Although the Finnish context characterizes the EC in the current study, it merely refers to the children's background as a sampling criterion. We kept in mind two criteria concerning the families of these children: at least one of the child's parents had to be of Finnish descent, and the family had to speak Finnish at home. It must be acknowledged that these children do not necessarily share a "Finnish" cultural identity (Warinowski, 2012).

The expatriate families that participated in our study had returned to a large city in Finland after a period abroad. The children in these families were attending a school of basic education (grades 1-9, ages 7-16) at the data-gathering stage of the research. Our study is thus an ex-postfacto investigation. This research setting was selected for practical reasons; for instance, it had to be possible for us to obtain responses covering different stages of the transition processes. Previously, a longitudinal research setting was attempted, but there was a dramatic drop-out rate of parents in the expatriation context. For the present study, we gathered the data using an online questionnaire that the parents completed after repatriation. Parents worked as the raters of their children's PA in transitions. Because some of the respondents were young children and the respondents had to reflect on feelings after several years, the children themselves could not be the respondents.

In Finland, there are no exact statistics about EC. Thus, we obtained the parents' contact information through 399 schools of basic education in eight large Finnish cities. The Finnish compulsory schooling system consists of 1 year of pre-primary education for 6-year-olds and 9 years of basic education for children aged 7 to 16 . Most of the schools of basic education are public schools. The cities were chosen because the urban environment is a typical space for locating expatriates (cf. Beaverstock, 2002). The response rate of the schools was 78\%, and the response rate of the returned questionnaires was $73 \%$. The final sample comprised 324 children and their families. Before enrolment in the research, parents gave written consent. Ethical principles like anonymizing data were strictly followed in the research process.

Most of the families in our sample were nuclear families (90\%). While living abroad, half of the families (49.5\%) lived in Europe, and one-fifth lived in North America (22\%). A little over half $(54.2 \%)$ of the families had lived abroad for 1 to 3 years. The number of girls $(54.2 \%)$ and boys $(45.8 \%)$ were similar although there was a slight overrepresentation of girls. Half $(49.2 \%)$ of the children who were in school while living abroad had attended a local school. Most (83.1\%) of the EC were in a school of basic education after repatriation to Finland. Thus, international schools were not the dominant schools for the Finnish EC in our sample. 
International Journal of Child, Youth and Family Studies (2020) 11(1): 1-22

\section{Measures}

To collect the data, we administered an online questionnaire (Webropol ${ }^{1}$ ). We examined PA using the ZSDS (Zung, 1972). The ZSDS uses a 4-point scale ranging from 1 (never) to 4 (almost always), where higher scores indicate lower PA. The ZSDS consists of 20 items dealing with the affective, physiological, and psychological components of PA (Ward et al., 2004). Other studies have named these three components differently, for example, as affective, physiological, and cognitive (Ward \& Rana-Deuba, 1999) or affective, somatic, and cognitive (Kitamura et al., 2004). Nevertheless, across studies, affective and cognitive symptoms have been fairly consistent (Kitamura et al., 2004). As noted earlier, the number of factors extracted in previous investigations varied from two to four.

There have been critiques of the "old" adaptation scales, and appeals for shorter versions of these scales (Demes \& Geeraert, 2013). Accordingly, the ZSDS in the present study consisted of 12 items instead of 20 (see Table 1). Of those items, we chose 11 from the original scale. The selection was based on three rationales. First, we looked at the symptoms mentioned in the previous TCK research. Second, some items fit well in the Finnish cultural context. Third, because there were several scales and measures in the questionnaire for parents, the number of items had to be restricted. We added one item ("putting on weight") to complete the scale with a similar but opposite item ("decreased appetite"). The scale was in Finnish. The translation from English to Finnish was done using a forward-backward translation method (to Finnish then back to English) with two translators (Beaton et al., 2000; see also Warinowski, 2012).

The design of the questionnaire was aimed at gathering data on the EC's PA in relation to expatriation and repatriation and to age, school success, and attitude toward expatriation and repatriation. The measures for the child-level factors examined age, school success, and attitudes toward moving abroad and back to Finland. For age, the age of the child in years (with one decimal when needed) was used. For school success, the traditional Finnish evaluation scale linked with school success (from 4, the worst, to 10, excellent) was used; this scale has been used in every Finnish school for decades. Thus, it was used in the current study because of its familiarity among parents. For questions about attitude toward moving, a 5-point Likert scale ranging from 1 (very negative) to 5 (very positive) was employed.

\section{Data Analyses}

All statistical analyses involved the use of the IBM Statistical Package for the Social Sciences (IBM-SPSS) version 23.0 and Mplus 7.4. The tests for the measures of the EC's PA comprised two stages.

First, to test the hypothesized two-factor structure of the measures for PA, we performed separate confirmatory factor analyses (CFAs) for the measures concerning expatriation and

\footnotetext{
${ }^{1}$ Webropol services can be found at https://webropol.com/
} 
International Journal of Child, Youth and Family Studies (2020) 11(1): 1-22

repatriation to test the two-factor measurement models in the expatriation and repatriation contexts.

Second, we constructed a structural equation model (SEM) to analyze the associations of the child-level variables (age, school success, and attitude toward moving) with the factors of PA and their contribution to PA. A SEM offers a general and flexible analytical framework for analyzing the hypothesized relationship between the variables, including not only directly observed variables but also latent constructs. Some main advantages of a SEM are that it can handle the measurement error of the variables, that the models can include multiple dependent variables simultaneously, and that it can handle data with missing values and non-normality effectively (e.g., Kline, 2015). According to a wide content analysis of acculturation research, only $6.6 \%$ of acculturation studies have used a path analysis or SEM as a data analysis method (Yoon et al., 2011). Thus, the present study broadens the methodological scope of the research on PA in cultural transitions by using a SEM (Cheung \& Rensvold, 2000).

We evaluated the goodness-of-fit of the estimated confirmatory factor analysis model and SEMs according to the following criteria: (a) a chi-squared test, (b) the comparative fit index (CFI), (c) the Tucker-Lewis index (TLI, aka NNFI), (d) the root-mean-square error of approximation (RMSEA), and (e) the standardized root-mean-square residual (SRMR). CFI and TLI values above 0.95 indicate a good model fit (e.g., Hooper et al., 2008; Hu \& Bentler, 1999; Little, 2013). For the RMSEA, values below 0.05 indicate a good fit between the hypothesized model and observed data (Hu \& Bentler, 1999; Little, 2013). Finally, SRMR values below 0.08 indicate a relatively good fit (Hu \& Bentler, 1999). We performed comparisons of the nested models using the SatorraBentler scaled chi-squared difference test (S-B $\Delta \chi^{2}$ test) and the difference of the comparative fit index $(\triangle \mathrm{CFI})$. There is evidence for a more restrictive model if the results of the $\mathrm{S}-\mathrm{B} \Delta \chi^{2}$ test is nonsignificant or if the value of the $\Delta$ CFI is less than 0.01 (Cheung \& Rensvold, 2002; Meade et al., 2008).

\section{Results}

The present study investigated EC's PA in the cultural transitions of expatriation and repatriation to answer the two research questions regarding the conceptual structure and role of three child-level variables. As noted above these questions were: (Q1) "What is the factorial structure of the PA of Finnish EC?" and (Q2) "What kind of a model can be constructed consisting of three child-level variables (age, school success, and attitude toward moving) that link with EC's PA in the cultural transitions of expatriation and repatriation?" The presentation of the results follows the order of the research questions and hypotheses.

\section{Factor Structure of Expatriate Children's Psychological Adjustment}

Table 1 presents the descriptive statistics of the EC's PA in relation to Q1. Concerning the EC's PA in general, the expatriate parents had a positive view of their children's PA. As Table 1 
International Journal of Child, Youth and Family Studies (2020) 11(1): 1-22

indicates, some items of the ZSDS had a rather low mean, while the standard deviation in the present study varied from 0.096 to 0.676 . 
International Journal of Child, Youth and Family Studies (2020) 11(1): 1-22

Table 1. Means and Standard Deviations of the ZSDS Items

\begin{tabular}{llcccc}
\hline \multirow{2}{*}{$\begin{array}{l}\text { ZSDS items } \\
\text { in this study }\end{array}$} & \multicolumn{1}{c}{$\begin{array}{c}\text { Original ZSDS items } \\
\text { in English }\end{array}$} & \multicolumn{3}{c}{ ZSDS I (Expatriation) } & \multicolumn{2}{c}{ ZSDS II (Repatriation) } \\
\cline { 3 - 6 } & & $M$ & $S D$ & $M$ & $S D$ \\
\hline zsds1 & Depressed affect & 1.24 & .48 & 1.24 & .55 \\
zsds2 & Crying spells & 1.40 & .63 & 1.23 & .52 \\
zsds3 & Sleep disturbances & 1.19 & .48 & 1.24 & .52 \\
zsds4 & Decreased appetite & 1.12 & .39 & 1.11 & .40 \\
zsds5 & Putting on weight & 1.10 & .42 & 1.07 & .32 \\
zsds6 & Pains, e.g., stomach ache, headache & 1.30 & .60 & 1.29 & .55 \\
zsds7 & Fatigue & 1.38 & .58 & 1.39 & .61 \\
zsds8 & Psychomotor agitation & 1.26 & .53 & 1.26 & .56 \\
zsds9 & Hopelessness & 1.09 & .35 & 1.08 & .33 \\
zsds10 & Irritability & 1.45 & .66 & 1.47 & .68 \\
zsds11 & Isolation & 1.17 & .46 & 1.14 & .43 \\
zsds12 & Panic attacks & 1.01 & .10 & 1.01 & .12 \\
\hline
\end{tabular}

Note: Scale range 1 (never) to 4 (almost always); $n=321-325$

Table 2 shows the correlations of the ZSDS items in general. There are many significant correlations between the items, especially in the repatriation context. These correlations would allow for testing a possible factor structure of PA at two time points (expatriation and repatriation). For example, depressed affect (zsds1) and isolation (zsds11) have significant correlations with several other items. Items such as panic attacks (zsds12), which have low correlations with all other items, may be difficult to fit into the factor solution (low factor loadings). Moreover, an item such as irritability (zsds10), which correlates with all other items, could also be problematic in the factor analysis because this item may have equally high loadings in several factors (equal size cross-loadings).

Table 2. Correlations Between the ZSDS Items

\begin{tabular}{lllllllllllll}
\hline & zsds1 & zsds2 & zsds3 & zsds4 & zsds5 & zsds6 & zsds7 & zsds8 & zsds9 & zsds10 & zsds11 & zsds12 \\
\hline zsds1 & & .55 & .38 & .32 & .15 & .44 & .44 & .31 & .59 & .55 & .56 & .01 \\
zsds2 & .35 & & .38 & .27 & .09 & .30 & .37 & .42 & .29 & .51 & .29 & -.03 \\
zsds3 & .21 & .41 & & .43 & .14 & .33 & .48 & .31 & .24 & .40 & .15 & -.03 \\
zsds4 & .23 & .31 & .40 & & -.06 & .34 & .42 & .23 & .26 & .31 & .22 & .04 \\
zsds5 & .28 & .07 & .15 & .04 & & .14 & .25 & .18 & .21 & .21 & .08 & -.02 \\
zsds6 & .20 & .29 & .23 & .38 & .24 & & .47 & .22 & .33 & .36 & .22 & -.04 \\
zsds7 & .36 & .27 & .27 & .34 & .29 & .44 & & .42 & .33 & .53 & .27 & .08 \\
zsds8 & .20 & .39 & .39 & .30 & .13 & .20 & .37 & & .22 & .47 & .14 & -.03 \\
zsds9 & .48 & .27 & .15 & .17 & .19 & .12 & .26 & .20 & & .38 & .44 & -.02 \\
zsds10 & .48 & .48 & .29 & .39 & .16 & .33 & .48 & .52 & .43 & & .50 & .10 \\
zsds11 & .47 & .21 & .16 & .32 & .18 & .26 & .32 & .21 & .42 & .47 & & .09 \\
zsds12 & .09 & .15 & .09 & .05 & -.02 & .17 & -.06 & .07 & .16 & .24 & .04 & \\
\hline
\end{tabular}

Note: Correlations for expatriation are shown in the lower part; repatriation is shown in the upper part [italics]. With $N=325, p<.05$ if $|r|>.11, p<.01$ if $|r|>.15, p<.001$ if $|r|>.19$. 
International Journal of Child, Youth and Family Studies (2020) 11(1): 1-22

We fitted a two-factor structure of PA to the data in both transitions. The hypothesized structure was based on the contents of the items, results of previous studies, and the preliminary examination of the items using an exploratory factor analysis (for preliminary analyses, see Warinowski, 2012). The first hypothetical factor is the physiological factor consisting of ZSDS items number 2 (crying spells), 3 (sleep disturbances), 4 (decreased appetite), 6 (pains), 7 (fatigue) and 8 (psychomotor agitation) in both the expatriation and repatriation contexts. The second factor is the affective factor, consisting of items number 1 (depressed affect), 9 (hopelessness), and 11 (isolation) in both contexts. We estimated the CFA models separately for each time point and evaluated the fit of the models. There was support for the two-factor CFA model at both time points: the goodness-of-fit of the model was acceptable in both the expatriation context, $\chi^{2}(26, N$ $=325)=45.25, \mathrm{CFI}=0.94, \mathrm{TLI}=0.92, \mathrm{RMSEA}=0.049$; and the repatriation context, $\chi^{2}(26, N=$ $323)=31.94, \mathrm{CFI}=0.98, \mathrm{TLI}=0.97, \mathrm{RMSEA}=0.045$. The Cronbach's alphas for the factors in expatriation (ZSDS I) were 0.74 for physiological problems and 0.71 for affective problems. In repatriation (ZSDS II), they were 0.77 (physiological) and 0.76 (affective). Table 3 shows the descriptive statistics of those two factors computed as the sum score variables based on the CFA model at both time points.

Table 3. Descriptive Statistics of the ZSDS Factors ( 1 = Expatriation, $2=$ Repatriation $)$

\begin{tabular}{lccccc}
\hline Factors & $N$ & Minimum & Maximum & $M$ & $S D$ \\
\hline Physiological 1 & 322 & 1.00 & 3.17 & 1.27 & 0.36 \\
Physiological 2 & 317 & 1.00 & 3.17 & 1.25 & 0.36 \\
Affective 1 & 325 & 1.00 & 3.00 & 1.17 & 0.34 \\
Affective 2 & 320 & 1.00 & 3.67 & 1.15 & 0.37 \\
\hline
\end{tabular}

Considering that the ZSDS questionnaire was intended to be used within the whole population, it was important to ensure that the measurement properties functioned similarly in the different subgroups of EC. Thus, we tested the model in two sets of subgroups, organized by gender into female $(N=175)$ and male $(N=149) \mathrm{EC}$, and by time into expatriation $(N=325)$ and repatriation $(N=323)$ subgroups. We examined the measurement invariance using multigroup and longitudinal CFA models with configural (M1), metric (M2), and scalar invariance (M3; e.g., Van de Schoot et al., 2015). For the gender subgroups, there was support for the model with strong measurement invariance (configural, metric, and scalar invariance: equal form, equal loadings, and equal intercepts) at both measurement points (Table 4). Between the measurement points, the model did not yield full scalar invariance. However, there was partial scalar invariance (M4) when the inequality of the intercepts was allowed for one item: ZSDS2 (crying spells). In other words, there was a time dependence for this one item. However, because five more items relating to physiological factors passed the scalar invariance test, the results support the invariance of the model (e.g., Little, 2013). 
International Journal of Child, Youth and Family Studies (2020) 11(1): 1-22

Table 4. ZSDS: Measurement Invariance

\begin{tabular}{|c|c|c|c|c|c|c|c|}
\hline & $\chi^{2}$ & $d f$ & CFI & TLI & RMSEA & S-B $\Delta \chi^{2}$-test & $\triangle \mathrm{CFI}$ \\
\hline \multicolumn{8}{|c|}{ Measurement invariance between gender, Expatriation } \\
\hline M1: Configural invariance & 75.87 & 52 & .926 & .898 & .053 & & \\
\hline M2: Metric invariance & 72.95 & 59 & .957 & .948 & .038 & $1.00(7) ; p=.995$ & .000 \\
\hline M3: Scalar invariance & 81.92 & 66 & .951 & .946 & .039 & $9.20(7) ; p=.951$ & .006 \\
\hline \multicolumn{8}{|c|}{ Measurement invariance between gender, Repatriation } \\
\hline M1: Configural invariance & 65.26 & 52 & .965 & .952 & .040 & & \\
\hline M2: Metric invariance & 70.03 & 59 & .971 & .964 & .034 & $5.66(7) ; p=.580$ & .000 \\
\hline M3: Scalar invariance & 77.12 & 66 & .971 & .968 & .032 & $5.59(7) ; p=.589$ & .000 \\
\hline \multicolumn{8}{|c|}{ Measurement invariance in time } \\
\hline M1: Configural invariance & 167.11 & 120 & .955 & .942 & .035 & & \\
\hline M2: Metric invariance & 175.80 & 127 & .953 & .943 & .034 & $9.03(7) ; p=.250$ & .002 \\
\hline M3: Scalar invariance & 200.15 & 136 & .938 & .930 & .061 & $32.90(9) ; p<.001$ & .015 \\
\hline M4: Partial scalar invariance & 183.67 & 135 & .953 & .947 & .033 & $5.45(8) ; p=.709$ & .000 \\
\hline
\end{tabular}

\section{Model of Three Child-Level Variables in Expatriate Children's Psychological Adjustment}

Next, we used SEM to examine the associations between the three child-level variables age, school success, and attitude toward moving — and the factors of PA, as well as their role in predicting PA. The main descriptive statistics of these three variables are as follows: On average, the EC were 4.8 years old ( $S D$ 3.24, min 0 , max 14) in the expatriation context and 8.2 years old (SD 2.30, min 6, $\max 15)$ in the repatriation context. According to their parents' assessments, the EC's success at school was mainly (62.7\%) "good" or "praiseworthy" while living abroad ( $M$ 8.82, $S D$ 0.97, min 5, $\max 10$, on a 7-point scale from 4 to 10). According to their parents, the EC's attitude toward moving was also quite positive for all measuring points ( $M$ 3.84-4.25, SD 0.941.19 ; $\min 1, \max 5$, on a 5 -point scale from 1 [very negative] to 5 [very positive]).

Figure 1 shows the SEM of the EC's PA. The goodness-of-fit of the model was acceptable, $\chi^{2}(d f=217, n=241)=306.52, \mathrm{CFI}=0.92, \mathrm{TLI}=0.91, \mathrm{RMSEA}=0.04, \mathrm{SRMR}=0.07$. As Figure 1 shows, all the regression paths were significant save for two.

In the expatriation context, Figure 1 shows that EC's attitudes toward moving were linked with both the physiological and affective factors of PA. Moreover, EC's age before moving abroad was connected with the affective factor of PA: older children had more affective problems living abroad. Success in school (SchSucc in Figure 1) while living abroad was also linked with the affective factor.

Figure 1. The SEM of the EC's $P A$ 


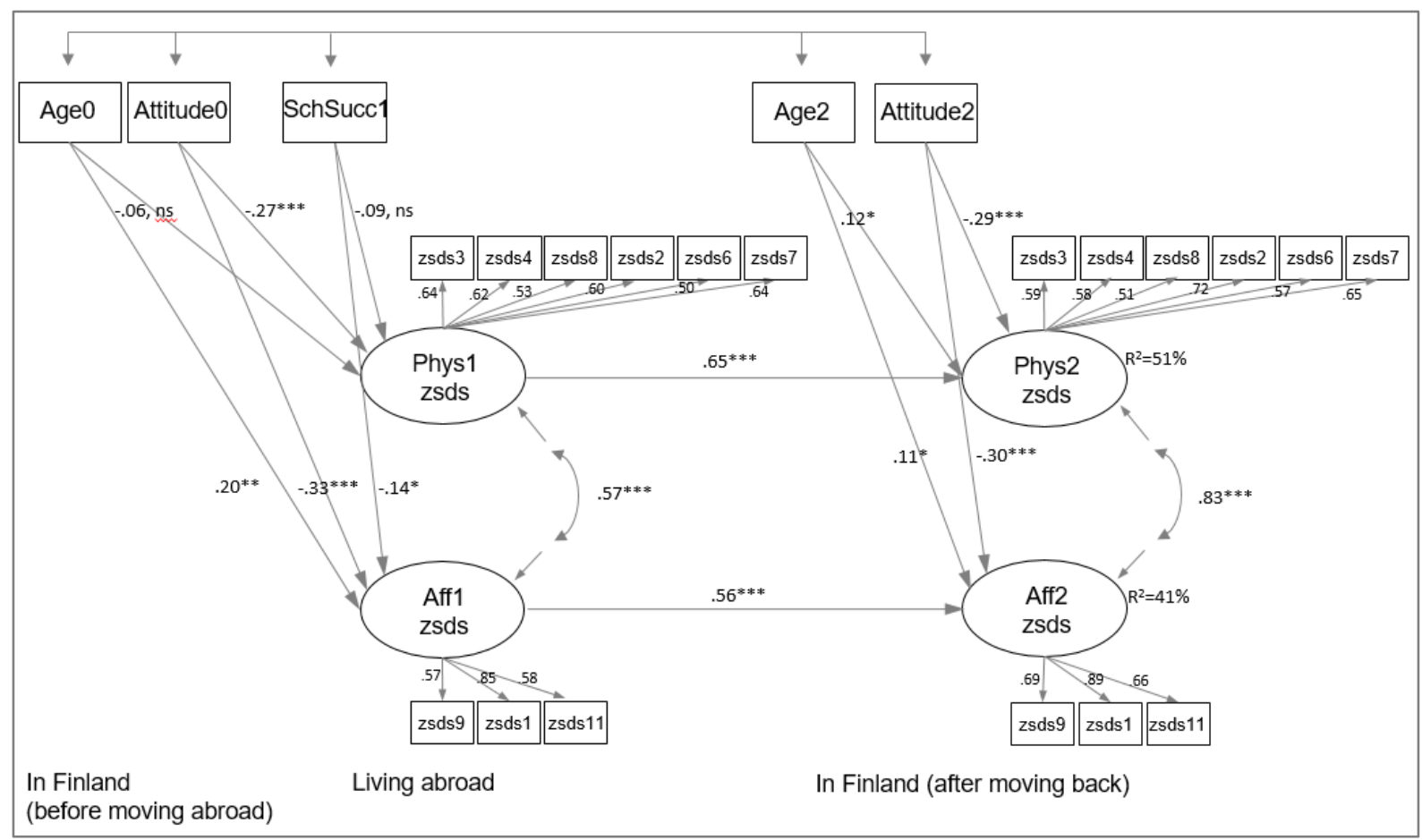

Note: The SEM of the three child-level variables (age, school success, and attitude toward moving) of EC's PA (physiological and affective factors; $* p<.05, * * p<.01, * * * p<.001$ ) in the cross-cultural transitions of expatriation and repatriation $(0=$ in Finland/before expatriation, $1=$ living abroad/after expatriation, $2=$ in Finland/after repatriation).

In the repatriation context, EC's attitudes were connected with both the physiological and affective factors of PA. Age before repatriation was linked with both factors as well. The paths from success in school while abroad to the PA factors after repatriation (Aff2 and Phys2) were left out from the final model as the path coefficients were nonsignificant and the likelihood ratio test supported the model without these connections, $\chi^{2}(d f=2, n=241)=.95, p=.621$. The longitudinal paths of the PA factors were significant between the same factors; that is, the autoregressive paths from Aff1 to Aff2 and from Phys1 to Phys2. The cross-lagged paths between the PA factors (longitudinal paths from Aff1 to Phys2, and from Phys1 to Aff2) were not significant, and they were omitted from the final model (the coefficients were nonsignificant and the likelihood ratio test supported the model without these connections, $\chi^{2}(d f=2, n=241)=2.08, p=.354$. This means that the physiological state at repatriation was predicted by the physiological state while abroad but did not have a longitudinal association with the affective factor. Correspondingly, the affective state while abroad predicted the affective state after moving back. The estimates of the standardized autoregression coefficients, $b=.65$ and $b=.56$ for physiological and affective factors respectively, indicated that the measured phenomena are quite stable over time: for example, children who had more physiological problems while abroad were likely to have them after repatriation too. 
International Journal of Child, Youth and Family Studies (2020) 11(1): 1-22

\section{Discussion and Conclusion}

The focus of the current study was on examining EC's PA in dual cultural transitions involving both expatriation and repatriation. The study aimed at transcending the two limitations of previous studies on cultural transitions that focused on a single transition, or only on adults. The study has two main results. First, a two-factor structure of PA comprising physiological and affective factors was extracted. Second, a model of PA with three child-level variables (age, school success, and attitude toward moving) was constructed.

The study highlights the relevance of the factor-structural examination of PA of Finnish EC by showing that a two-factor structure of the ZSDS fit the data pertaining to EC (Chida et al., 2004; Zung, 1972). This two-factor CFA model received support in both the expatriation (ZSDS I) and repatriation (ZSDS II) contexts. Additionally, our findings indicate that PA has similarities in the factor structure, regardless of the participants' backgrounds. However, the two-factor structure in the current research for Finnish EC is different from that in previous studies, where common cognitive and affective factors have been found (e.g., Kitamura et al., 2004). The current research did not highlight common cognitive variables. In addition, physiological (also called "somatic" in previous studies) symptoms were found to be quite significant in our study. This was partly a matter of conceptual grouping; for example, in Kitamura et al.'s (2004) study, there were symptoms of fatigue in the affective factor, while in the current research, they belonged to the physiological factor. The present study broadens conceptual knowledge of PA by making visible both physiological and affective factors; we believe that these broad dimensions require further refinement. As well, the measurement model of PA showed a good model fit and full configural and metric invariance in the investigated sample of EC.

Concerning the second research question, the main finding of the present study was that child-level variables could apply to a model of PA for EC. The model indicates that for younger EC, positive attitudes toward moving and good success in school ease their PA. The EC's attitude toward moving emerged as a major variable in our model. In addition, we showed that PA appears to be an active process, where, as per the quantitative data, the child has an agentic role. This shows that children don't just passively "adjust": EC's attitudes play a part in the adjustment process. These findings have practical importance for clinicians and health care practitioners for both prevention and treatment activities. Typically, childhood study perspectives with an agentic view on children have employed qualitative methods (e.g., Clark et al., 2014). Now, through the use of quantitative methods, we have shown that it is also possible to consider children's agency. Methodologically, this broadens the scope of the research on PA in cultural transitions using SEM analyses. We believe that the main strength of our study is that it will expand the focus of PA research.

From a broad cultural perspective, the current study has special theoretical and practical relevance from two viewpoints. 
International Journal of Child, Youth and Family Studies (2020) 11(1): 1-22

First, the study compared two transitional processes. Previous research has mainly focused on only one transition of adult migrants, namely expatriation. In examining the dual processes of expatriation and repatriation of EC, our study provides further knowledge about two cultural transitions. Summarizing the findings from this dual viewpoint, the factor structure was identical for both processes (Q1). The study also showed that the factors had similar means between the two time points (Table 4). In addition, both the physiological and affective factors were permanent in both contexts in the PA model (Q2). This suggests that expatriation and repatriation may have some similarities where PA is concerned. But we also draw attention to our finding that EC's attitudes are especially important in the repatriation process and therefore suggest that the repatriation process merits more attention.

The second strength of this study is that it helps us to put the children of expatriate families in the spotlight. We highlight here that children's attitudes are involved in the PA process that they experience. Children are not just "luggage" that adults take with them when they move abroad and when they return to their country of origin (Selmer \& Lam, 2004). We also believe that given the strength and generalizability of our findings, further investigations into children's experiences of expatriation and repatriation should employ both qualitative and quantitative methods. Moreover, emotional and other kinds of support should be offered to children in the expatriation context, and even more so in the repatriation context. Parents should pay attention to their children's feelings in the contexts of expatriation and repatriation, listen to them, give emotional support, and make time for being together.

\section{Limitations}

We also acknowledge that our study has some notable limitations. First, the research was an ex-post-facto study, which can affect the findings because of the difficulty of remembering details after several years have passed. Unfortunately, this limitation could not be avoided because a longitudinal research setting was not an option (see the "Subjects and Procedure" section).

Second, the parents evaluated their children's PA, whereas researchers have typically used the ZSDS as a self-rating scale (see the "Subjects and Procedure" section for the rationale behind the decision to have parents as respondents). Parents' view of their children's PA in general was that there were only a few PA problems on a large scale. In what we report here, parents' views of their children differed from the interview data gathered from children in an earlier part of this project in that the parents' quantitative assessments were more positive than their children's qualitatively expressed views (Warinowski, 2012). It would therefore be important to get data from older children by using the ZSDS to know whether this difference is a matter of measuring differently or indicates real differences between parents' views of their children and the children's views of themselves.

Third, the present study concentrated on only one European group of EC: Finnish EC. It is hard to know how context-specific these results are, or in other words how important the cultural Finnish context of the children is. It may be helpful to consider only Finnish EC, European EC, or 
EC in general. As non-English speakers, Finnish children differ, at least with respect to their language situation, from English-speaking American or British EC with schools and expatriate communities where their own language is used. We therefore believe that more studies concentrating on non-English and European EC's PA are needed.

The results and limitations of the present study lead us to suggestions for further studies on EC's PA: Dual transition processes merit further examination in PA studies. Furthermore, future studies should include qualitative approaches to uncover the experiences of the EC themselves (Warinowski, 2012). Additionally, contextual approaches, such as family-level studies, warrant more thorough investigations (Warinowski, 2012). To examine adjustment and adaptation processes, future studies should employ more process-oriented methods when studying PA in cultural transitions. Finally, we believe there is a need for further studies involving cultural comparisons of EC's PA in different cultural contexts.

Overall, the results of the present study contribute to the understanding of PA in general and EC's PA in particular. In the era of increasing global mobility, EC are not the only children or individuals undergoing multiple transitional processes that involve PA. The unique contribution of the current study is that it produced knowledge about EC's PA in novel contexts of dual cultural transitions. In an increasingly globalized world, the findings concerning PA processes in the present study are significant in clinical and other support contexts where professionals are working for the mental well-being of children. 
International Journal of Child, Youth and Family Studies (2020) 11(1): 1-22

\section{References}

Allik, J. (2013). Bibliometric analysis of the Journal of Cross-Cultural Psychology during the first ten years of the new millennium. Journal of Cross-Cultural Psychology, 44, 657-667. doi: $10.1177 / 0022022112461941$

Beaton, D. E., Bombardier, C., Guillemin, F., \& Ferraz, M. B. (2000). Guidelines for the process of cross-cultural adaptation of self-report measures. Spine, 25, 3186-3191. doi:10.1097/00007632-200012150-00014

Beaverstock, J. V. (2002). Transnational elites in global cities: British expatriates in Singapore's financial district. Geoforum, 33, 525-538. doi:10.1016/S0016-7185(02)00036-2

Berry, J. W., Phinney, J. S., Sam, D. L., \& Vedder, P. (2006). Immigrant youth in cultural transition. Acculturation, identity, and adaptation across national contexts. Lawrence Erlbaum.

Bhatia, S., \& Ram, A. (2009). Theorizing identity in transnational and diaspora cultures: A critical approach to acculturation. International Journal of Intercultural Relations, 33, 140149. doi:10.1016/j.ijintrel.2008.12.009

Brown, P., \& Lauder, H. (2009). Globalization, international education, and the formation of a transnational class? In T. S. Popkewitz \& F. Rizvi (Eds.), Globalization and the study of education. 108th yearbook of the National Society for the Study of Education. Part II (pp. 130-147). Wiley-Blackwell. doi:10.1111/j.1744-7984.2009.01165.x

Cheung, G. W., \& Rensvold, R. B. (2000). Assessing extreme and acquiescence response sets in cross-cultural research using structural equations modeling. Journal of Cross-Cultural Psychology, 31, 187-212. doi:10.1177/0022022100031002003

Cheung, G. W., \& Renswold, R. B. (2002). Evaluating goodness-of-fit indexes for testing measurement invariance. Structural Equation Modeling, 9, 233-255. doi:10.1207/S15328007SEM0902_5

Chida, F., Okayama, A., Nishi, N., \& Sakai, A. (2004). Factor analysis of Zung Scale scores in a Japanese general population. Psychiatry and Clinical Neurosciences, 58, 420-426. doi:10.1111/j.1440-1819.2004.01277.x

Chirkov, V. (2009a). Critical psychology of acculturation: What do we study and how do we study it, when we investigate acculturation? International Journal of Intercultural Relations, 33, 94-105. doi:10.1016/j.ijintrel.2008.12.004

Chirkov, V. (2009b). Summary of the criticism and of the potential ways to improve acculturation psychology. International Journal of Intercultural Relations, 33, 177-180. doi:10.1016/j.ijintrel.2009.03.005 
International Journal of Child, Youth and Family Studies (2020) 11(1): 1-22

Chiu, C.-Y., Lonner, W. J., Matsumoto, D., \& Ward, C. (2013). Cross-cultural competence: Theory, research, and application. Journal of Cross-Cultural Psychology, 44, 843-848. doi:10.1177/0022022113493716

Clark, A., Flewitt, R., Hammersley, M., \& Robb, M. (2014). Understanding research with children and young people: Introduction. In A. Clark, R. Flewitt, M. Hammersley, \& M. Robb (Eds.), Understanding research with children and young people (pp. 1-10). Sage. doi:10.4135/9781526435637.n1

Costigan, C. L., Koryzma, C. M., Hua, J. M., \& Chance, L. J. (2010). Ethnic identity, achievement, and psychological adjustment: Examining risk and resilience among youth from immigrant Chinese families in Canada. Cultural Diversity and Ethnic Minority Psychology, 16, 264-273.

Demes, K. A., \& Geeraert, N. (2013). Measures matter: Scales for adaptation, cultural distance, and acculturation orientation revisited. Journal of Cross-Cultural Psychology, 45, 91-109. doi: $10.1177 / 0022022113487590$

Dobson, M. E. (2009). Unpacking children in migration research. Children's Geographies, 7, 355-360. doi:10.1080/14733280903024514

Fail, H. (2007). The potential of the past in practice: Life histories of former international school students. In M. Hayden, J. Levy, \& J. Thompson (Eds.), The Sage handbook of research in international education (pp. 103-112). Sage. doi:10.1177/1475240904047358

Fail, H., Thompson, J., \& Walker, G. (2004). Belonging, identity and third culture kids: Life histories of former international school students. Journal of Research in International Education, 3, 319-338.

Fröjd, S. A., Nissinen, E. S., Pelkonen, M. U. I, Marttunen, M. J., Koivisto, A.-M., \& KaltialaHeino, R. (2008). Depression and school performance in middle adolescent boys and girls. Journal of Adolescence, 31, 485-498. doi:10.1016/j.adolescence.2007.08.006

Grimshaw, T., \& Sears, C. (2008). "Where am I from?" "Where do I belong?" The negotiation and maintenance of identity by international school students. Journal of Research in International Education, 7, 259-278. doi:10.1177/1475240908096483

Haslberger, A., \& Brewster, C. (2008). The expatriate family: An international perspective. Journal of Managerial Psychology, 23, 324-346. doi:10.1108/02683940810861400

Hooper, D., Coughlan, J., \& Mullen, M. (2008). Structural equation modelling: Guidelines for determining model fit. Electronic Journal of Business Research Methods, 6, 53-60. 
International Journal of Child, Youth and Family Studies (2020) 11(1): 1-22

Hu, L., \& Bentler, P. M. (1999). Cutoff criteria for fit indexes in covariance structure analysis: Conventional criteria versus new alternatives. Structural Equation Modeling, 6, 1-55. doi:10.1080/10705519909540118

Kagitcibasi, C. (2005). Autonomy and relatedness in cultural context. Implications for self and family. Journal of Cross-Cultural Psychology, 36, 403-422. doi:10.1177/0022022105275959

Kanno, Y. (2000). Bilingualism and identity: The stories of Japanese returnees. International Journal of Bilingual Education and Bilingualism, 3, 1-18. doi:10.1080/13670050008667697

Kano Podolsky, M. (2004). Cross-cultural upbringing: A comparison of the "Third Culture Kids" framework and "Kaigai/Kikoku-shijo" studies. Contemporary Society: Kyoto Women's University Bulletin, 6, 11-28. Retrieved from http://hdl.handle.net/11173/340

Kitamura, T., Hirano, H. Chen, Z., \& Hirata, M. (2004). Factor structure of the Zung Self-Rating Depression Scale in first-year university students in Japan. Psychiatry Research, 128, 281287. doi:10.1016/j.psychres.2004.06.003

Kline, R. (2015). Principles and practice of structural equation modeling (4th ed.). Guilford.

König, J. (2009). Moving experience: Dialogues between personal cultural positions. Culture Psychology, 15, 97-119. doi:10.1177/1354067X08099617

Little, T. (2013). Longitudinal structural equation modeling. Guilford.

MacBeth, A., \& Gumley, A. (2012). Exploring compassion: A meta-analysis of the association between self-compassion and psychopathology. Clinical Psychology Review, 32, 545-552. doi:10.1016/j.cpr.2012.06.003

McCarty, C. A., Mason, W. A., Kosterman, R., Hawkins, J. D., Lengua, L. J., \& McCauley, E. (2008). Adolescent school failure predicts later depression among girls. Journal of Adolescent Health, 43, 180-187. doi:10.1016/j.jadohealth.2008.01.023

Meade, A. W., Johnson, E. C., \& Braddy, P. W. (2008). Power and sensitivity of alternative fit indices in tests of measurement invariance. Journal of Applied Psychology, 93, 568-592.

Murphy, E. (2003). Monolingual international schools and the young non-English-speaking child. Journal of Research in International Education, 2, 25-45. doi:10.1177/1475240903021002

Nathanson, J. Z., \& Marcenko, M. (1995). Young adolescents' adjustment to the experience of relocating overseas. International Journal of Intercultural Relations, 19, 413-424. doi:10.1016/0147-1767(95)00027-9 
International Journal of Child, Youth and Family Studies (2020) 11(1): 1-22

Nette, J., \& Hayden, M. (2007). Globally mobile children: The sense of belonging. Educational Studies, 33, 435-444. doi:10.1080/03055690701423614

Nguyen, A.-M. D., \& Benet Martínez, V. (2013). Biculturalism and adjustment: A meta-analysis. Journal of Cross-Cultural Psychology, 44, 122-159. doi:10.1177/0022022111435097.

Nieto, S. (2008). Culture and education. Yearbook of the National Society for the Study of Education, 107(1), 127-142. doi:10.1111/j.1744-7984.2008.00137.x

Oishi, S., Krochik, M., Roth, D., \& Sherman, G. D. (2012). Residential mobility, personality, and subjective and physical well-being: An analysis of cortisol secretion. Social Psychological and Personality Science, 3, 153-161. doi:10.1177/1948550611412395

Passik, S. D., Lundberg, J. C., Rosenfeld, B., Kirsh, K. L., Donaghy, K., Theobald, D., Lundberg, E., \& Dugan, W. (2000). Factor analysis of the Zung Self-Rating Depression Scale in a large ambulatory oncology sample. Psychosomatics, 41, 121-127. doi:10.1176/appi.psy.41.2.121

Romera, I., Delgado-Cohen, H., Perez, T., Caballero, L., \& Gilaberte, I. (2008). Factor analysis of the Zung Self-Rating Depression Scale in a large sample of patients with major depressive disorder in primary care. BMC Psychiatry, 8. Retrieved from https://www.ncbi.nlm.nih.gov/pmc/articles/PMC2257949/

Schwartz, S. J., Unger, J. B., Zamboanga, B. L., \& Szapocznik, J. (2010). Rethinking the concept of acculturation: Implications for theory and research. American Psychologist, 65(4), $237-$ 251.

Searle, W., \& Ward, C. (1990). The prediction of psychological and sociocultural adjustment during cross-cultural transitions. International Journal of Intercultural Relations, 14(4), 449-464. doi:10.1016/0147-1767(90)90030-Z

Selmer, J., \& Lam, H. (2004). “Third-culture kids" future business expatriates? Personnel Review, 33(4), 430-445. doi:10.1108/00483480410539506

Shah, D., \& Lund, D. W. (2007). Spousal perspective of expatriate family adjustment. International Journal of Diversity in Organizations, Communities and Nations, 7(2), 93101. doi:10.18848/1447-9532/CGP/v07i02/39359

Sussman, N. M. (2002). Testing the cultural identity model of the cultural transition cycle: Sojourners return home. International Journal of Intercultural Relations, 26(4), 391-408. doi:10.1016/S0147-1767(02)00013-5

Suutari, V., \& Brewster, C. (2003.) Repatriation: Empirical evidence from a longitudinal study of careers and expectations among Finnish expatriates. International Journal of Human Resource Management, 14(7), 1132-1151. 
International Journal of Child, Youth and Family Studies (2020) 11(1): 1-22

Szkudlarek, B. (2010). Reentry - A review of the literature. International Journal of Intercultural Relations, 34(1), 1-21. doi:10.1016/j.ijintrel.2009.06.006

Van de Schoot, R., Schmidt, P., \& De Beuckelaer, A. (Eds.) (2015). Measurement invariance. Frontiers Media. Retrieved from https://www.frontiersin.org/researchtopics/1695/measurement-invariance\#overview

Ward, C., \& Kagitcibasi, C. (2010). Introduction to "acculturation theory, research and application: Working with and for communities." International Journal of Intercultural Relations, 34(2), 97-100. doi:10.1016/j.ijintrel.2010.02.001

Ward, C., \& Kennedy, A. (1992). Locus of control, mood disturbance, and social difficulty during cross-cultural transitions. International Journal of Intercultural Relations, 16(2), 175-194. doi:10.1016/0147-1767(92)90017-O

Ward, C., \& Kennedy, A. (1993a). Psychological and sociocultural adjustment during crosscultural transitions: A comparison of secondary students overseas and at home. International Journal of Psychology, 28(2), 129-147. doi:10.1080/00207599308247181

Ward, C., \& Kennedy, A. (1993b). Where's the "culture" in cross-cultural transition? Comparative studies in sojourner adjustment. Journal of Cross-Cultural Psychology, 24(2), 221-249. doi:10.1177/0022022193242006

Ward, C., \& Kennedy, A. (1994). Acculturation strategies, psychological adjustment, and sociocultural competence during cross-cultural transitions. International Journal of Intercultural Relations, 18(3), 329-343. doi:10.1016/0147-1767(94)90036-1

Ward, C., Leong, C.-H., \& Low, M. (2004). Personality and sojourner adjustment: An exploration of the Big Five and the cultural fit proposition. Journal of Cross-Cultural Psychology, 35(2), 137-151. doi:10.1177/0022022103260719

Ward, C., Okura, Y., Kennedy, A., \& Kojima, T. (1998). The U-Curve on trial: A longitudinal study of psychological and sociocultural adjustment during cross-cultural transition. International Journal of Intercultural Relations, 22(3), 277-291. doi:10.1016/S0147$\underline{1767(98) 00008-X}$

Ward, C., \& Rana-Deuba, A. (1999). Acculturation and adaptation revisited. Journal of CrossCultural Psychology, 30(4), 422-442. doi:10.1177/0022022199030004003

Ward, C., \& Searle, W. (1991). The impact of value discrepancies and cultural identity on psychological and sociocultural adjustment of sojourners. International Journal of Intercultural Relations, 15(2), 209-224. doi:10.1016/0147-1767(91)90030-K 
International Journal of Child, Youth and Family Studies (2020) 11(1): 1-22

Warinowski, A. (2011a). Contemporary emigration on the family level: Finnish expatriate families. In E. Heikkilä \& S. Koikkalainen (Eds.), Finns abroad: New forms of mobility and migration (pp. 153-171). Institute of Migration. Migration studies C21. Turku:

Painosalama.

Warinowski, A. (2011b). Finnish expatriate families and their children: A complementary viewpoint. In G. Bell-Villada, N. Sichel, F. Eidse, \& E. Neil Orr (Eds.), Writing out of limbo: International childhoods, global nomads and third culture kids (pp. 291-312). Cambridge Scholars Publishing.

Warinowski, A. (2012). Maailmalle yhtenä, takaisin toisena? Suomalaisten ekspatriaattiperheiden lapset kulttuurisissa siirtymissä [Abroad as one, back as the other? Children of Finnish expatriate families in cultural transitions] (Dissertation in Finnish with an English abstract; Research A42). Turku, Institute of Migration.

Weinreich, P. (2009). "Enculturation," not "acculturation": Conceptualising and assessing identity processes in migrant communities. International Journal of Intercultural Relations, 33(2), 124-139. doi:10.1016/j.ijintrel.2008.12.006

Yoon, E., Langrehr, K., \& Ong, L. Z. (2011). Content analysis of acculturation research in counseling and counseling psychology: A 22-year review. Journal of Counseling Psychology, 58(1), 83-96.

Yoon, E., Lee, R. M., \& Goh, M. (2008). Acculturation, social connectedness, and subjective well-being. Cultural Diversity and Ethnic Minority Psychology, 14(3), 246-255.

Zung, W. W. K. (1972). A cross-cultural survey of depressive symptomatology in normal adults. Journal of Cross-Cultural Psychology, 3(2), 177-183. doi:10.1177/002202217200300206 